\title{
Música, cosmopolitismos e cidades: experimentações juvenis das migrações em São Paulo ${ }^{1}$ \\ Music, cosmopolitisms and cities: youngsters experiences of migration in São Paulo
}

\section{Simone Luci Pereira}

Docente da Universidade Paulista, Brasil. Doutora em Ciências Sociais pela Pontifícia Universidade Católica de São Paulo, Brasil. Pós-doutorado na Universidade Federal do Estado do Rio de Janeiro, Brasil, no Conselho Latinoamericano de Ciências Sociais, Argentina, e na Universidade Federal do Rio de Janeiro, Brasil. E-mail: simonelp@uol.com.br

\begin{abstract}
Resumo:
Este artigo apresenta aspectos da pesquisa em curso sobre práticas musicaismidiáticas de jovens migrantes na cidade de São Paulo em suas construções identitárias e estratégias de visibilidade/audibilidade. As atividades de coletivos juvenis ligados à música em suas articulações com grupos de ativismo cultural, ativismo migrante e aqueles ligados aos usos da cidade são o foco aqui. Articulamos uma discussão sobre migrações, cosmopolitismos e cidades em tempos globais e analisamos as práticas e os sentidos políticos destes grupos e o papel da própria cidade como local de fixos e fluxos engendrando espaços de interação, formação de localidades ligadas à música, ativismo e etnicidade. A metodologia contempla etnografia em locais de entretenimento e debates organizados por estes atores e aponta para formas de associações e interações comunicacionais entre migrantes e brasileiros em que música, entretenimento, consumo e socialidades têm papel aglutinador numa rede de fluxos diversos, não dissociadas de atividades de cunho político.
\end{abstract}

\section{Palavras-chave:}

Juventude; Migração; Práticas Musicais-Midiáticas; Cosmopolitismos; Cidade.

\begin{abstract}
:
This article presents aspects of the ongoing research on musical-mediatic practices of young migrants in São Paulo in their identity constructions and visibility/audibility strategies. The activities of youth groups linked to music in their articulations with groups of cultural activism, migrant activisms and those linked to the uses of the city are the focus here. We articulate a discussion of migrations, cosmopolitanisms and cities in global times and analyze the political practices and meanings of these groups and the role of the city as a place of fixed and flowed elements engendering spaces of interaction, formation of localities linked to music, activism and ethnicity. The methodology contemplates ethnography in places of entertainment and debates
\end{abstract}

\footnotetext{
${ }^{1}$ Este artigo é uma versão ampliada e atualizada do texto "Práticas musicais-midiáticas juvenis na esfera da migração cubana em S.Paulo/Brasil: tradições, cosmopolitismos e sentidos políticos", apresentado na I Bienal Latinoamericana de Infâncias e Juventudes, ocorrida em Manizales/Colômbia, em novembro de 2014.
}

INTERIN, v. 22, n. 1, jan./jul. 2017. ISSN: 1980-5276. 
organized by these actors and points to associations and interactive communication forms between migrants and Brazilians in which music, entertainment, consumption and socialities play a unifying role in a network of diverse flows, not dissociated from political nature activities.

\section{Keywords:}

Youth; Migration; Musical-Mediatic Practices; Cosmopolitisms; City.

Nos estudos sobre grupos juvenis e culturas urbanas deparamo-nos com formas de experimentação da interculturalidade (CANCLINI, 2007) e de cosmopolitismos (HANNERZ, 1999; DELANTY, 2008) de várias ordens, nas quais as zonas de contato, conflito e negociação de sentidos culturais e identitários se fazem presentes, bem como formas de atuação juvenis colaborativas e em redes de cooperação que os tornam atores sociais emergentes (REGUILLO, 2014).

Em cidades como São Paulo a presença de jovens migrantes advindos da América Latina hispânica, África e outros locais delineia um contexto diaspórico experimentado por brasileiros e estrangeiros em suas práticas musicais e artísticas e naquilo que estas engendram em termos identitários, políticos, comunicacionais e midiáticos. A música, assim, para além de seus elementos estéticos (que não serão analisados neste artigo), mostra-se como elemento importante nas diásporas da atualidade, coadunando questões de representação cultural, agência, poder, mediação, comoditização e trocas interculturais (APARÍCIO; JÁQUEZ, 2003).

Como aponta Appadurai (2004), poderíamos falar no cultural (adjetivo) mais do que em cultura (substantivo): a dimensão cultural nos é útil para ressaltar o caráter relacional e não isolado das identidades e como recurso heurístico do qual lançamos mão para abordar as diferenças e os encontros culturais e para compreender as vicissitudes dos encontros vividos de forma particular pelos jovens em cidades globais ou ordinárias (ROBINSON, 2006), em suas interações, confrontações, negociações. Nestes lugares, identidades, pertenças, estranhamentos, formas de engajamento, imaginação e sentidos políticos têm de negociar espaços, mútuas influências e formas de colaboração, colaborando para a edificação de perspectivas 
de análise de-coloniais ${ }^{2}$ (QUIJANO, 2005; MIGNOLO, 2007) na compreensão de experiências vividas na América Latina.

As experiências de deslocamentos, mobilidades e migrações mostram-se na atualidade como fenômenos que tocam de maneira contundente as formas de sentir, pensar e conhecer o mundo e a diferença. Contextos diaspóricos constroem subjetividades que lidam a todo tempo com entrelugares (BHABHA, 2001) e zonas intersticiais (CANCLINI, 2007) de negociação e conflito, gerando múltiplas identificações e pertencimentos, e desfocando a noção clássica de identidade fixa e homogênea. Analisar as narrativas (discursivas, musicais, midiáticas, políticas) construídas pela experiência migrante mostra-se tarefa a um só tempo difícil e instigante, dada a riqueza e a complexidade de seus conteúdos múltiplos que não se enquadram facilmente em dicotomias como reconhecimento ou recusa.

Neste artigo, interpretamos algumas das práticas musicais-midiáticas de jovens migrantes na cidade de São Paulo no que trazem de construções identitárias e de estratégias de visibilidade/audibilidade. Partindo das atividades musicais, o objetivo tem sido seguir os atores em suas associações ${ }^{3}$, nas articulações que estes jovens migrantes estabelecem com coletivos de ativismo cultural, ativismo migrante e aqueles ligados aos usos da cidade, em forma de redes associativas e comunicacionais, salientando os sentidos políticos dessas interações e o papel da própria cidade como espaço de fixos e fluxos (SANTOS, 2006) engendrando formas de interação, formação de localidades ligadas à música, ativismo e etnicidade, onde os cosmopolitismos jogam importante papel.

Com uso de entrevistas e etnografia em locais de entretenimento e debates organizados por estes atores - buscando perscrutar suas rotas pela cidade, sem cair em dicotomias que separam presencial versus virtual - temos percebido relações de colaboração variadas entre brasileiros e migrantes oriundos da América Latina hispânica (os quais tem sido nosso foco de pesquisa nos últimos anos) bem como

\footnotetext{
${ }^{2}$ A perspectiva decolonial se refere a uma proposta teórica, epistemológica e política de um grupo de intelectuais latino-americanos, numa radicalização do argumento pós-colonial neste continente. $\mathrm{O}$ "giro decolonial" proposto atualiza a discussão crítica sobre as questões que envolvem a América Latina, salientando a colonialidade do saber e do poder advindos do norte global e assumindo posturas epistemológicas e teóricas disruptivas frente a isso.

${ }^{3}$ Baseamo-nos nas postulações da Teoria-Ator-Rede (LATOUR, 2012), na ênfase em seguir os rastros dos atores, seus movimentos e associações; perceber e analisar ações sutis e não explícitas e estáveis como quer a Sociologia clássica. Uma ênfase, assim, numa performatividade do social e seu viés político como meio para pensar a vida social, em conexões instáveis e provisórias.
}

INTERIN, v. 22, n. 1, jan./jul. 2017. ISSN: 1980-5276. 
associações com jovens migrantes oriundos de outras partes do mundo. Nestas associações, as práticas musicais e artísticas tem papel aglutinador, como nós que fazem parte de uma rede de fluxos e interações comunicacionais diversas, permeadas e não dissociadas de atividades mais diretamente ligadas ao ativismo político ligado à migração (como nas ações do coletivo Visto Permanente), ao acesso à informação (no caso do Coletivo Digital) e aos usos da cidade (com foco nas ações do coletivo Cidade Lúdica).

Neste complexo de associações e fluxos, em que é possível interpretar práticas musicais-midiáticas nas quais entretenimento, lógicas de consumo e socialidades não se separam de atividades de cunho político e de engajamentos diversos, percebemos aspectos presentes nas formas de experimentação de cosmopolitismos e nas diásporas em tempos globais. Em outras palavras, vamos verificando o quanto a música e suas práticas de produção, performance, escuta, divulgação, consumo, entretenimento, identificação (elementos todos que fazem parte do que chamamos de prática musical-midiática) são catalisadoras de sentidos políticos e construções de formas de ser jovem numa cidade global, onde a experiência das migrações transnacionais e da cultura midiática têm importante papel. Mais ainda, ressaltamos o quanto estes fluxos de informações, de capitais, de pessoas, de culturas, de imaginários, de sonoridades e de diversas formas de ativismos políticos são salientados em contextos urbanos contemporâneos cosmopolitas como São Paulo.

\section{Práticas musicais-midiáticas diaspóricas: redes de colaboração e sentidos políticos}

O panorama das migrações contemporâneas ocorre no contexto das novas condições econômicas globais (COGO, 2010), aonde a cultura da mobilidade vem se integrando às experiências individuais e coletivas. Como transnacionais vem sendo nomeadas as migrações contemporâneas (LEVITT; GLICK SCHILLER，2010), exigindo perspectivas de análise que também ultrapassem as fronteiras nacionais. Se por muito tempo as ciências sociais e humanas fizeram uso de termos como 
migrações ou exílios para abordar práticas de mobilidades relacionadas especificamente a motivações econômicas ou políticas, unidirecionais e em termos nacionais, as noções de migração transnacional ou diáspora buscam abarcar processos multifocais, multidirecionais, multicausais tentando dar conta ainda das simultaneidades temporais e espaciais envolvidas nestes processos. Esta mudança de perspectiva e nomeação relaciona pesquisas e reflexões mais recentes nos campos da Antropologia, Estudos Culturais, Comunicação, colaborando no entendimento de culturas tradicionais, locais, populares, massivas e globais em suas múltiplas relações. Os meios de comunicação eletrônicos juntamente com os movimentos migratórios trazem uma instabilidade na produção das subjetividades e imaginários midiáticos, onde imagens e sons em movimento criam representações sobre outridades sem categorias fixas de espaço/tempo. No entanto, como bem lembra Appadurai (2004), esta dinâmica não pode ser entendida apenas como criadora de fractais globais de identidade e de espectadores desterritorializados; ocorre, sim, uma produção de localidades, nas quais fluxos globais e locais negociam sentidos, como temos observado nas práticas migrantes em São Paulo.

Compreender os espaços midiáticos no contexto das migrações em cidades como São Paulo mostra-se importante na medida em que o âmbito comunicacional vai se delineando como central tanto pelas formas de interação de grupos que mantem relações com o local de origem ao mesmo tempo em que criam vínculos na terra escolhida (ou forçada) para viver, como também porque grupos migrantes têm nas mídias potentes meios de expressão (COGO et al., 2012), trabalho, busca por visibilidade/audibilidade e possibilidades de auto representação.

Nestas "esferas públicas de diáspora" (APPADURAI, 2004), repletas de sentidos, conteúdos e disputas políticas, estão presentes novas realidades que fazem cruzar etnopaisagens e mediapaisagens diversas, disjuntivas e conflitantes (APPADURAI, 2004), as quais exercem efeitos significativos na imaginação global e nas formas de interação com o Outro. Esta imaginação (que não se confunde com fantasia) envolve a arte, a música, as mídias e é produzida coletivamente acionando sentidos de pertencimento e produção de localidades, como potentes narrativas midiáticas (RINCÓN, 2006). 
Temos acompanhado nos últimos anos os trajetos materiais, simbólicos, virtuais de jovens migrantes ligados à música na cidade de São Paulo. Analisando as práticas musicais-midiáticas em torno do quinteto formado por jovens cubanos Batanga e Cia, alguns aspectos dos cosmopolitismos globais e periféricos (discutiremos isso mais a frente) podem ser interpretados. Como sugere Retis (2014), nos parece fundamental seguir estes atores pela cidade, em suas rotas migrantes que envolvem apresentações musicais, vida cotidiana, interações comunicacionais, consumos culturais, construções identitárias - no caso destes, em torno do latino no Brasil (PEREIRA, 2015) - interações com outros grupos e coletivos juvenis, entre outros aspectos.

O Batanga e Cia é um quinteto instrumental formado por jovens migrantes cubanos, que se apresenta num circuito de festas e eventos "latinos", bem como em espaços como o Jazz nos Fundos. Com três anos de duração, este grupo tem ajudado a impulsionar uma certa cena latina na cidade de viés mais instrumental e que recebe um público jovem interessado em música cubana e caribenha em geral mais ligada ao latin jazz e fusões com ritmos e sonoridades caribenhas mais antigas, como rumba, batanga, bolero. Os locais de atuação deste grupo contemplam uma área da cidade a Vila Madalena e região - ligada a um certo circuito alternativo de festas e eventos. Vale ressaltar que este segmento de música latina não é o único existente no circuito mais amplo de música latina em São Paulo, contemplando também áreas do centro da cidade e também na zona sul, onde predominam respectivamente casas de regetón/ cumbia e salsa mais comercial.

Como já apontamos em outro artigo (PEREIRA, 2015), a designação latino no Brasil é uma complexa construção identitária nós/outros envolvendo reconhecimentos e estranhamentos de maneira conflituosa, guardando séculos e com diferentes roupagens que ajudam a constituir uma noção de latino como um Outro, o que advém da América Latina hispânica. Sem espaço para aprofundar esta análise neste artigo, salientamos apenas o quanto o papel de jovens migrantes oriundos da América Latina que fala espanhol vivendo em São Paulo tem colaborado na elaboração de uma busca por reconhecimentos mútuos neste cenário. Uma atuação

INTERIN, v. 22, n. 1, jan./jul. 2017. ISSN: 1980-5276. 
política identitária ${ }^{4}$ ligada à música, à dança, ao entretenimento e aos circuitos de consumo cultural que tenta estreitar as relações entre brasileiros e hispânicos, na busca pela afirmação de identidades comuns, em que pesem aí as próprias contradições que as identidades migrantes apresentam, reforçando estereótipos por vezes, mas também trazendo fissuras a um discurso hegemônico sobre a alteridade.

Nesse sentido, vemos o quanto o recurso da cultura e sua performatividade (YUDICE, 2002), mostra-se presente em espaços diaspóricos globais, em que identidades são construídas, reconstruídas, encenadas, performatizadas de acordo com sentidos que articulam o comercial, o econômico, o cultural e o político, perfazendo cidadanias culturais e comunicacionais. Cidadanias estas que parecem trazer outras formas de latinidade que não as hegemônicas, as quais possibilitam a agência de representações identitárias forjadas pelos próprios migrantes, para além dos binarismos estruturantes e ideológicos que reforçam estereótipos colonizantes (APARICIO; CHAVEZ-SILVERMAN, 1997). Nesse processo, incorporam e rejeitam paradoxalmente aspectos das representações hegemônicas, numa negociação ambígua pelas bordas em que deixam de ser objetos passivos para serem agentes e na qual as categorias fixas desestabilizam-se.

Percebemos isso na busca que faz o Batanga e Cia. em ser não apenas um grupo que toca salsa. Eles buscam um resgate e revigoração de ritmos e gêneros musicais cubanos das décadas de 1940/50, na busca por se diferenciarem de um circuito mais comercial de salsa na cidade (e no mundo), para terem distinção e prestígio na hierarquia presente entre grupos migrantes (ROMÁN-VELÁZQUEZ, 2009) e na busca por uma ideia de autenticidade cubana e caribenha no amplo espectro desta latinidade musical aqui consumida.

$\mathrm{Na}$ mobilidade e fluxo existente entre os grupos musicais latinos, temos a presença de uma das integrantes do Batanga e Cia em outro grupo musical recémformado e que vem atuando na cidade: o Trio Acústico las Américas. Formado por jovens oriundos de Cuba, Brasil e Equador, o trio busca desenvolver uma linguagem diferenciada, trazendo a diversidade de ritmos e estilos latino-americanos com

\footnotetext{
${ }^{4}$ Esboçado de maneira mais explícita na criação de um coletivo chamado Coletivo de Bandas Latinoamericanas lançado em 2015, reunindo grupos musicais diversos que tenham em suas práticas, sonoridades e integrantes latinos e brasileiros, na busca por um reconhecimento do Brasil como integrante da América Latina.
}

INTERIN, v. 22, n. 1, jan./jul. 2017. ISSN: 1980-5276. 
influências do latin jazz e improvisações, misturados com músicas autorais e "peças selecionadas dos países de origem dos integrantes", como consta no flyer de divulgação do grupo ${ }^{5}$. Utilizando piano, vibrafone e percussão, buscam uma viagem pelas sonoridades e cadências de toda a América Latina, desde o candombe uruguaio até rumba cubana, passando pela música brasileira.

Nesse sentido, mostram-se em conflito e negociação as relações entre tradição e cosmopolitismo, fazendo repensar lógicas e formas de participação política entre jovens migrantes, onde tradição, identidade, performances musicais e usos midiáticos surgem como potentes mecanismos para se mostrarem, representarem a si mesmos, se apropriarem dos espaços da cidade como atores políticos emergentes e reivindicarem identidades não apenas autóctones, mas entre tendências locais e globais.

Nestes processos de produção e consumo cultural podemos perceber a articulação com hábitos e estilos de vida em metrópoles ligados a parcelas de jovens das camadas médias; formas de consumo onívoro (PETERSON e KERN, 1996), que se quer progressista e alternativo, e que embora apresente elementos de busca por distinção, também aponta para outras formas de resistir ao massivo, ao hegemônico mainsntream. O gosto por objetos culturais e musicais mais alternativos mostrase nos traços de cosmopolitismo presentes nos processos interculturais entre fluxos locais, globais, regionais. Estas características de um certo cosmopolitismo alternativo se destacam como elementos da vida urbana de certos espaços da cidade nos quais se imbricam noções de autenticidade e distinção social que estes grupos musicais congregam e acionam para discutirmos as complexidades do campo cultural, migrante e identitário.

Questões relacionadas ao consumo, entretenimento (e até exotização em alguns casos) presentes nos contextos diaspóricos acionam e trazem à tona lógicas conflituosas em que estão presentes identidades, formas de autorrepresentação e de visibilidade/audibilidade, questões de capital simbólico, consumo da alteridade. Nos próprios processos culturais da globalização, ao mesmo tempo em que há fortes movimentos no sentido de padronização de gostos e modas, há também

\footnotetext{
${ }^{5}$ Informação disponível em:

$<$ https://www.facebook.com/pg/trioacusticodelasamericas/about/?ref=page_internal $>$. Acesso em: 06/06/2017.
}

INTERIN, v. 22, n. 1, jan./jul. 2017. ISSN: 1980-5276. 
certo valor (inclusive mercadológico) para noções de tradição e autenticidade, que ganham distinção em certos circuitos culturais, numa certa louvação da diferença que muitas vezes é vazia, acrítica e formuladora de novas formas de hierarquização, domínio, produção de estereótipos.

Entretanto, frisamos, fugindo de interpretações dicotômicas não restringimos a análise dos jovens músicos migrantes aqui descritos a este processo, mas apontamos as fissuras e ambivalências presentes em suas práticas e imaginários, percebendo suas lógicas no que têm de hegemônicas e também de potenciais possibilidades de negociação de sentidos, formação de identidades múltiplas, híbridas, abertas às escutas fabuladoras e afetos. A música (para além de sua dimensão estética) e suas práticas parecem servir como lócus privilegiado para analisar as interações sociais, culturais e os agenciamentos identitários e políticos na cidade, como mola propulsora de encontros, significações partilhadas, que extrapolam gostos e pertencimentos em homologia a gêneros e estilos musicais, proporcionando trocas afeitas à interculturalidade.

Nesse sentido é que, na busca por seguir estas rotas migrantes em São Paulo, nos deparamos com a atuação de integrantes dos grupos musicais em atividades de produção cultural mais ampla, se articulando a outros coletivos como o Cidade Lúdica e o Visto Permanente, salientando aspectos dos atravessamentos recentes verificados entre experiências migratórias e comércio étnico (COGO, 2010), mídias e reivindicação de espaços urbanos.

O coletivo Visto Permanente existe desde $2015^{6}$ e se propõe como um "espaço virtual vivo no qual se representam as comunidades imigrantes de São Paulo através da sua expressividade artística e cultural”, numa espécie de museu virtual ativo com um acervo das novas culturas migrantes e reivindicação da presença migrante na cidade e do direito a ela. Realizado pelo coletivo Viramundo, integrado por jovens brasileiros e migrantes, buscam dar visibilidade para o patrimônio urbano das culturas migrantes e suas formas de resistência, salientando que este patrimônio é também paulistano. O trabalho consiste em gravar, filmar, produzir material audiovisual de artistas migrantes da cidade buscando contribuir para sua visibilidade/audibilidade numa luta contra xenofobia e desigualdade por via da

\footnotetext{
${ }^{6}$ Projeto contemplado pelo Edital "Redes e Ruas" de Cultura Digital, Inclusão e Cidadania da Prefeitura de São Paulo.
}

INTERIN, v. 22, n. 1, jan./jul. 2017. ISSN: 1980-5276. 
transformação dos "imaginários sociais"7. Percebem-se colaborações e associações entre este grupo e organizações como o Coletivo Digital (que trabalha pela democratização e acesso à sociedade da informação), espaço de exposições de artistas migrantes e do primeiro show do Trio Acustico Las Américas.

Vale lembrar que o Trio foi formado em decorrência destes contatos de alguma forma viabilizados pela atuação do Visto Permanente, que filmou e divulgou os trabalhos artísticos de duas das integrantes do grupo separadamente para o seu acervo (a cubana Claudia Rivera, e a equatoriana Emilia Desiré), possibilitando esta integração, a idealização de um novo grupo musical que vem atuando na cidade, em áreas da periferia e da zona oeste e formas de trabalho para estes sujeitos.

Nestas ações migrantes, há uma preocupação constante e recorrente (em suas narrativas) que vai além da visibilidade migrante e dos direitos civis de permanência no país ou ainda de luta e resistência contra xenofobia, trabalho e direitos humanos. Todas estas pautas estão no escopo do ativismo migrante do Visto Permanente que é ainda acrescida por uma luta pelo direito à cidade e pela mobilidade, numa preocupação com os usos do espaço público por migrantes e minorias, trazendo noções de cidadania que vão além da jurídica e formal, mas passando por suas formas culturais e comunicacionais.

Nesta preocupação com o direito à cidade, o Visto Permanente tem realizado ações de cooperação e associativismo com outros espaços e movimentos. Um deles é o Al Janiah, que existe desde 2015 e é um misto de bar, restaurante, espaço político de trocas e encontros; de propriedade de um imigrante palestino, emprega migrantes e refugiados recém-chegados no Brasil, se auto intitulando como um espaço de resiliência e resistência de um pedaço da Palestina Livre aberto a quem quiser chegar. ${ }^{8}$ O local tem atraído um público cada vez maior ao centro velho de São Paulo, uma vez que vem se tornando um espaço referencial de lutas pelo direito à migração, contra xenofobia e racismo, promovendo debates, saraus e apresentações musicais de artistas migrantes oriundos da África e também da América Latina.

Outro destes coletivos é o Cidade Lúdica. Nascido em 2016, busca a promoção, articulação, fortalecimento e empoderamento de ações realizadas por

\footnotetext{
${ }^{7}$ Informação disponível em: <http://www.vistopermanente.com/>. Acesso em: 16/12/2016.

${ }^{8}$ Informação disponível em: < https://www.facebook.com/Al-Janiah-183073728713846/?fref=ts $>$. Acesso em: 16/12/2016.
}

INTERIN, v. 22, n. 1, jan./jul. 2017. ISSN: 1980-5276. 
coletivos, grupos e outros agentes sociais que buscam ressignificar e transformar a cidade dando ênfase a sua dimensão lúdica e coletiva e como local de pertencimento ${ }^{9}$, criando uma rede de ajuda mútua e colaboração para a viabilização de ações realizadas na cidade como espaço ativo e orgânico. Entre suas atividades, estão debates mensais sobre obras de autores de referência sobre cidades contemporâneas, bem como apresentação de projetos e visitas de campo que vem ocorrendo em várias áreas da cidade, promoção de eventos, mesas-redondas que tenham na pauta restauração de áreas verdes, geração de cultura nas ruas, promoção de cidadania e ações formativas. Em suma, um ativismo em torno dos usos da cidade e de ocupação dos espaços públicos. Entre seus integrantes, há jovens da área de comunicação, cinema, artes, fotografia, atuando em segmentos que fazem parte do movimento/coletivo; entre eles há o projeto Ouvidoria, um núcleo de resgate de depoimentos e memórias, coordenado por Sheila Calgaro.

Num evento por eles realizado em junho de 2016, o Nós, a Cidade - um ciclo de debates e mesas-redondas durante um dia ocorrido na UNIBES Cultural, região oeste da cidade - uma das sessões foi dedicada ao tema Imigrantes e a Cidade: como os imigrantes transformam a cena sociocultural paulistana, que contou com a colaboração e organização de um dos músicos que integra o Batanga e Cia, Pedro Bandera, produtor cultural ativo nas ações da cultura latina na cidade. A mesaredonda contou com a participação de ativistas migrantes como Ives Berger (peruano diretor do El Guia Latino e do festival Soy Latino), Viviana Peña (colombiana assessora da Coordenação de Políticas para Migrantes da Secretaria de Direitos Humanos e Cidadnia da Prefeitura de São Paulo), Oriana Jara (chilena diretora da PAL - Presença da América Latina) e Cristina de Branco (portuguesa, integrante do Visto Permanente).

Vamos verificando uma rede formada por estes atores migrantes, em ações que ligam música e atividades lúdicas e de entretenimento às diversas formas de empoderamento migrante, as quais se cruzam com questões de gênero e étnicas, perfazendo esferas públicas de diáspora (APPADURAI, 2004) de múltiplas colaborações, de debates e de tomadas de posição políticas e identitárias, em que geografias desiguais de poder (ROMÁN-VELASQUEZ, 2009) podem negociar

${ }^{9}$ Informação disponível em: <http://cidadeludica.com.br/>. Acesso em: 16/12/2016.

INTERIN, v. 22, n. 1, jan./jul. 2017. ISSN: 1980-5276. 
sentidos e onde é possível reclamar o espaço público e imaginar outros futuros para as cidades, não contemplados nos sentidos de cidades globais hegemônicas, em que São Paulo, para além de sua história e temporalidade local, se liga e articula com práticas e sentidos de outras cidades centrais ou periféricas do mundo.

\section{Migrações e mídias, cidades e cosmopolitismos vistos do Sul - algumas conclusões}

Estes jovens migrantes vão mostrando que modernização e desenvolvimento nos moldes capitalistas e institucionais não se constituem nas únicas formas de viver urbano (ROBINSON, 2006), destacando formas outras, informais e potentes, seja nas formas de cosmopolitismo alternativo e não ligado necessariamente aos modelos, objetos e valores do mundo anglófono ou europeu, seja em articulações com outros grupos na cidade que vem atuando com atores políticos emergentes ligados ao ativismo migrante e pelos usos da cidade. Atentando para narrativas (verbais, discursivas, musicais, etc.) que constroem sentidos para suas trajetórias como sujeitos migrantes, temos a arte, a música, o ativismo como formas privilegiadas dos sujeitos darem conta de expressar a singularidade de suas experiências (FERREIRA, 2010).

A partir das práticas musicais-midiáticas migrantes em São Paulo, vamos adentrando em questões mais amplas que dizem respeito às realidades migrantes em cidades globais e às abordagens cosmopolitas dos fenômenos que nelas ocorrem.

Vai se esboçando uma escala global, transnacional ou cosmopolita das cidades (HANNERZ, 1997; 1999), atenta às novas formas de comunicação, operações financeiras globais que criam uma desterritorialização da produção e da gestão do sistema, afetando a percepção do espaço e do tempo e levando a uma perspectiva cosmopolita expressa teórica e metodologicamente (BECK, 2007) que nos permita compreender os fenômenos imbricados nessas cidades. Isso porque, articulado ao processo de desterritorialização de fluxos de informações e finanças, vão se constituindo indivíduos, hábitos, gostos e práticas que circulam pelo planeta gerando estilos de vida similares. Este processo, longe de apenas 
homogeneizar as culturas, dialoga e negocia com os aspectos locais, salientando a presença de fluxos globais e locais em negociação e conflito em dinâmicas próprias da interculturalidade. Hannerz (1997) argumenta ainda sobre o uso do vocabulário da interconectividade e do cosmopolitismo metodológico, refutando a noção de mosaico ou justaposição, uma vez que vivemos envolvidos em vários tipos de mobilidade geográfica e midiática gerando fluxos que se desenrolam no tempo e no espaço, asseverando o lugar das cidades-mundo para uma cultura transnacional, com interações em múltiplas combinações.

Pensando nos cosmopolitismos presentes nas experiências migrantes aqui analisadas, observa-se que elas não se restringem às inserções e interações com o norte global, reconhecendo a existência de uma multiplicidade de projetos cosmopolitas no mundo (DELANTY, 2008), geradas em qualquer contexto onde haja processos de autotransformação surgidas do encontro com a alteridade, negociação e zonas de contato entre culturas. Deixa-se para trás uma noção de cultura associada a grupos fechados, distantes e pretensamente puros, uma vez que o contato com o diferente traz um repensar sobre o Mesmo, problematizando a dicotomia nós/outros e próprio/estrangeiro, em que as posições são revisadas à luz da perspectiva da alteridade.

A proposta de um cosmopolitismo crítico e dialógico envolve uma perspectiva epistêmica que ultrapasse tanto o universalismo das proposições kantianas e iluministas de cosmopolitismo, como também a fragmentação e a difusa e controversa ideia de diversidade e relativismo vazio contidas em certas tendências pós-modernas. Este cosmopolitismo crítico apontaria para um pós-universalismo (DELANTY, 2008) que se localiza no entre ou nas mediações entre local e global.

Nos contextos diaspóricos ou migrantes como os que aqui apresentamos e analisamos, mostram-se traços deste cosmopolitismo que tem como pressuposto a mescla e a reelaboração de culturas e identidades e onde a música e as artes jogam um importante papel; um cosmopolitismo que não necessariamente tem relação com processos europeus ou estadunidenses, mas que se esboça num cosmopolitismo periférico (PRYSTHON, 2002), que vai se delineando empiricamente, colaborando para uma epistemologia alternativa à ideia corrente de globalização como homogeneização e padronização (ainda que com

INTERIN, v. 22, n. 1, jan./jul. 2017. ISSN: 1980-5276. 
esta mantenha relações), dizendo respeito às formas como o local responde aos desafios lançados pelo global.

Cosmopolitismos que guardam intensa relação com as cidades e o viver urbano contemporâneos. Sassen (1991) analisa o fenômeno das cidades globais, aonde as disposições geográficas de centralidade e marginalidade vão se constituindo em mais nítidas confluências, salientando a paradoxal presença de sujeitos periféricos ao lado dos privilegiados em situações de conflito e assimetria ocasionada pela polarização econômica e social dadas pelas próprias condições globais das metrópoles, em que fluxos intensos de capital e informações ocorrem. O que estas cidades globais trariam em si, segundo Sassen, é a potência de serem locais estratégicos para a formação de identidades e comunidades transnacionais, possuindo diferentes atores em lutas por visibilidade e legitimidade, fazendo com que surjam e coexistam várias centralidades.

Robinson (2006), entretanto, aponta o quanto os estudos urbanos necessitam de uma perspectiva pós-colonial, no sentido de não se limitarem aos cânones ou modelos de cidade do norte global, posicionando cidades da América Latina e da África por exemplo, como modelos de viver urbano que desafiam a lógica modernizante e desenvolvimentista e propondo ainda uma um olhar cosmopolita e comparativo para os estudos de cidades na atualidade. Fugindo da dicotomia entre as "inovadoras cidades globais" e as "imitativas cidades do terceiro mundo", Robinson enfatiza as realidades, vicissitudes, e potências das cidades ordinárias, em sua complexidade e diversidade; mais ainda, salienta o quanto é necessário atentar para fluxos que muitas vezes não são tão visíveis ou evidentes, mas que dinamizam o viver urbano (VARGAS; ROMÀN-VELAZQUEZ, 2011).

Com esta perspectiva interpretamos as rotas e trajetos dos jovens migrantes aqui analisados, em suas formas de associações e criação de vínculos e agências que podem ser mais efêmeras, menos permanentes, mas que ajudam a mudar espaços e feições da cidade de São Paulo, atuando na criação de lugares (não apenas físicos) ligados à música, às artes, ao consumo cultural, prenhes de formas de agenciamento político, identitário, interações e socialidades possíveis, tais como temos observado no Al Janiah, nas atividades do Visto permanente, do Cidade Lúdica e nas 
performances $^{10}$ musicais do Batanga e Cia. e do Trio Acústico Las Américas. Os usos da cidade realizados pelos fluxos das rotas migrantes destes jovens nos chamam a atenção pelas formas de experimentar os lugares, (re)utilizar e (re)imaginar espaços, em que a cidade assume sua dimensão de mediação e comunicação, atrelando modos de viver que são atravessados pelas feições midiáticas da vida urbana. Vê-se um processo em curso de reinvindicação de espaços como seus (ROMÁN-VELAZQUEZ, 2014), em que sensos de identidade e lugar são acionados na mudança que trazem no caráter das cidades.

Traços de cosmopolitismos alternativos ou periféricos mostram-se nestes processos ocorridos em cidades globais ou ordinárias, perfazendo formas de manejar e negociar sentidos que revelam maneiras de se envolver com o Outro. Isso colabora para desfazer a noção de que o cosmopolitismo estaria atrelado apenas às disposições e práticas de uma elite mundial sofisticada que viaja ao redor do globo e incorpora diferentes práticas, vocabulários e sentidos, não se restringindo ao mundo ocidental. Segundo Ribeiro (2003), os intensos movimentos migratórios globais trouxeram à tona complexas segmentações étnicas nacionais e urbanas, redes transnacionais e culturas diaspóricas que, interligadas à cultura midiática, criaram um cosmopolitismo popular e alimentaram processos, visões e experimentações diferenciadas de globalização.

Este artigo buscou relacionar as experiências migratórias aqui interpretadas tendo como foco as práticas musicais-midiáticas no que articulam de sentidos de pertença, identidade e visibilidade/audibilidade, com associações e ativismos políticos ligados à migração de maneira mais ampla e aos usos da cidade, destacando o quanto estas experiências agem nas formas de viver urbano e atuam em sentidos de cosmopolitismo ordinários, periféricos, subalternos (PRYSTHON, 2002). Sem desconsiderar geografias de poder e fronteiras que se fazem presentes quando falamos de fluxos de pessoas, narrativas e imaginários, em que a noção de sul global se mostra como questão discursiva e pragmática (RESENDE, 2014), buscamos uma proposição que enfatiza, assim, uma perspectiva epistemológica para a discussão

10 Performance aqui entendida em seu sentido ritualístico ou zumthoriano, que aciona emissor/obra/ouvinte num mesmo processo, em que a escuta, participação e interação com o público, ambiência, o espaço físico, os sons e ruídos ao redor também são levados em conta, fazendo parte da performance.

INTERIN, v. 22, n. 1, jan./jul. 2017. ISSN: 1980-5276. 
de questões socioculturais e midiáticas globais, sem dicotomias sul/norte, mas sublinhando processos que se dão nas periferias ou nas margens - algo que as práticas dos jovens migrantes aqui analisados nos fazem refletir.

\section{REFERÊNCIAS}

APARICIO, F.; CHÁVEZ-SILVERMAN, S. (Eds.). Tropicalizations: transcultural representations of latinidad. Hanover/EUA: University Press of New England, 1997.

APARICIO, F.; JÁQUEZ, C. (Eds.). Musical migrations: transnationalism and cultural hybridity in latin/o America. Vol. 1. New York: Palgrave Macmillan, 2003.

APPADURAI, A. Dimensões culturais da globalização. Lisboa: Teorema, 2004.

BECK, U. The cosmopolitan condition: why methodological nationalism fails. Theory, culture e society. n. 24 v. 7-8. p. 286-290, 2007.

BHABHA, H. O local da cultura. Belo Horizonte: Ed. UFMG, 2001.

CANCLINI, N. G. A globalização imaginada. São Paulo: Ed. Iluminuras, 2007.

COGO, D. Comunicação, cidadania e transnacionalismo. In: BARBALHO, A. et al. (Orgs.). Comunicação para a cidadania: temas e aportes teórico-metodológicos. São Paulo: INTERCOM. p. 41-64. 2010.

COGO, D. et al. (Ed.). Diásporas, migrações, tecnologias da comunicação e identidades transnacionais. Bellaterra: Institut de la Comunicació, Universitat Autònoma de Barcelona, 2012.

DELANTY, G. La imaginación cosmopolita. Revista CIDOB d'Afers Internacionals. Fronteras: Transitoridad y dinâmicas interculturales, n. 82 p. 25-49, 2008.

FERREIRA, A. Processamentos alterativos e subjetivos: os dispositivos da elaboração migrante. In: FERREIRA, A. et al. (Orgs.). A experiência migrante: entre deslocamentos e reconstruções. Rio de Janeiro: Garamond/Faperj, p. 15-18, 2010 .

HANNERZ, U. Cosmopolitas e locais na cultura global. In: FEATHERSTONE, Mike (Org). Cultura global: nacionalismo, globalização e modernidade. Petrópolis: Vozes. p. 251-266, 1999.

HANNERZ, U. Fluxos, fronteiras, híbridos: palavras-chave da antropologia transnacional. Mana. n.3 v.1. p 7-39, 1997. 
LATOUR, B. Reagregando o social: uma introdução à Teoria Ator-Rede. Salvador: Edufba, 2012.

LEVITT, P.; GLICK SCHILLER, N. Conceptualizar a simultaneidade: uma visão da sociedade assente no conceito de campo social transnacional. In: MARQUES, M. (Coord.). Estado-Nação e migrações internacionais. Lisboa: Livros Horizonte, p. 28-85, 2010.

MIGNOLO, W. La ideia de America Latina: la herida colonial y la opción decolonial. Barcelona: Gedisa, 2007.

PEREIRA, S. L. Consumo e escuta musical, identidades, alteridades: reflexões em torno do circuito musical "latino" em São Paulo/Brasil. Chasqui - Revista Latinoamericana de Comunicación. CIESPAL-Equador, n.128, jul/set 2015.

PETERSON, R.; KERN, R. Changing highbrow taste: from snob to omnivore. American Sociological Review. n. 61. v. 5. p. 900-907, 1996.

PRYSTHON, A. Cosmopolitismos periféricos: ensaios sobre modernidade, pósmodernidade e estudos Culturais na América Latina. Recife: Ed. Bagaço, 2002.

QUIJANO, A. Colonialidade do poder, eurocentrismo e América Latina. In: LANDER, E. (Org.). A colonialidade do saber: eurocentrismo e ciências sociais perspectivas latino-americanas. Buenos Aires: CLACSO, p. 227-278. 2005.

REGUILLO, R. Re-pensar la participación juvenil: nuevas formas, nuevos retos. Conferência Magistral. IV Escuela de Posgrado de la REd INJU y del Progranma de Invcestigación em Ciencias Sociales, Niñez y Juventud. El Colef Tijuana/Mexico, 2014.

RESENDE, F. The global south: conflicting narratives and the invention of geographies. IBRAAZ. Platform 008, 2014. Disponível em: $<\mathrm{http}: / / \mathrm{www}$.ibraaz.org/usr/library/documents/main/the-global-south.pdf $>$. Acesso em: $17 / 12 / 2016$.

RETIS, J. ¿Consumidores o ciudadanos? Prácticas de consumo cultural de los inmigrantes latino-americanos en España. Fronteras - Revista de Ciencias Sociales y Humanidades, v. 1, n. 1., p. 71-96, 2014.

RIBEIRO, G. Postimperialismo: cultura y politica en el mundo contemporâneo. Barcelona: Gedisa, 2003

RINCÓN, O. Narrativas mediáticas: o cómo se cuenta la sociedad del entretenimento. Barcelona: Gedisa, 2006.

ROBINSON, J. Ordinary Cities. Between Modernity and Development. London: Routledge, 2006. 
ROMÁN-VELÁZQUEZ, P. Latin Americans in London and the dynamics of diasporic identities. In: KEOWN, M. et al. (Eds.). Comparing postcolonial diásporas. UK: Palgrave, Macmillan. p. 104-124, 2009.

ROMÁN-VELÁZQUEZ, P. Latin Americans in London: claims over the identity of place as destination. In: SARMENTO, C. e CAMPOS, R. (Eds.). Popular \& visual culture: Contexts of Design, Circulation and Consumption. Newcastle-upon-Tyne: Cambridge Scholars Publishing. p. 23-40, 2014.

SASSEN, S. The global city: New York, London, Tokio. Princeton: Princeton University Press, 1991.

SANTOS, M. A natureza do espaço: tempo e técnica, razão e emoção. São Paulo: Edusp, 2006.

VARGAS, A.; ROMÁN-VELÀZQUEZ, P. Latin American urban cultural studies: unique texts, ordinary cities. Westminster Papers in Communication and Culture. v. 8., n.1., p.131-153, 2011.

YUDICE, G. El recurso de la cultura: usos de la cultura en la era global. Barcelona: Gedisa, 2002.

Recebido em: 19.12 .2016

Aceito em: 31.03.2017

INTERIN, v. 22, n. 1, jan./jul. 2017. ISSN: 1980-5276. 